REFLEXIONES 

Fecha de entrega: 12 de noviembre de 2008

Fecha de aprobación: 14 de marzo de 2009

\title{
LA SEDUCCIÓN ESTÉTICA Y EL AMOR INFELIZ EN SØREN KIERKEGAARD
}

\author{
THE AESTHETIC SEDUCTION AND THE UNHAPPY \\ LOVE IN SOREN KIERKEGAARD
}

Héctor Rodríguez L. ${ }^{1}$

Después dirá Nietzsche: La existencia y el mundo sólo se justifican eternamente como un fenómeno estético. Julio Cortazar-Imagen de Jhon Keats

\section{Resumen}

Este texto presenta un acercamiento al estadio estético de la vida en relación con las diferencias que se establecen entre el seductor estético y el amante infeliz desde Søren Kierkegaard. En la introducción, se hará la presentación de Kierkegaard en el contexto intelectual de la Dinamarca que acogió al pensador en el s. XIX mediante algunos datos biográficos y la referencia a los estadios de la existencia. Luego, se tratarán tres temas, a saber: la descripción del estadio estético de la vida de acuerdo con la elección; la seducción estética como fantasía desde el seductor y el amor como melancolía desde el amante infeliz.

\begin{abstract}
This text is an approach to the aesthetic stage in life in relationship with the differences established between the aesthetical seducer and the unhappy lover from Søren Kierkegaard on. In the introduction, we will present Kierkegaard in the intelectual context of the Denmark of the thinker and with the use of some biographical data and the reference to the stages of life. Later, we will raise three issues: the description of the aesthetic stage
\end{abstract}

1 Estudiante de la Licenciatura en Filosofía y Lengua Castellana de la Universidad Santo Tomás, Bogotá (II-2008). El texto se encuentra asesorado por el profesor Manuel Palacio licenciado en Filosofía y Letras de la misma Universidad. 
of life in relationship with the election, the aesthetic seduction as a fantasy as seen from the seducer and love as melancholy as seen from the unhappy lover.

\section{Introducción}

Søren Aabye Kierkegaard es quizás el más grande pensador e intelectual danés de épocas recientes. Nació el 5 de mayo de 1813 en la fría Copenhague, para morir en ella misma el 11 de noviembre de 1855. Aquel mes de mayo en el que nació debió resultar demasiado frío como para despertar en su espíritu sentimientos profundos que sólo se atreven a experimentar almas que se impresionan ante lo sencillo y que descubren cosas maravillosas donde nadie más las ve. El frío, fue ese frío danés el que lo acompañó a lo largo de sus cuarenta y cuatro años de vida hasta el mismo mes de noviembre en el que falleció tras desmayarse en la calle, un frío capaz de hacer buscar lo más cálido para el espíritu de la mano de lo eterno. Su apasionante estilo de vida es muestra de ello.

Desde temprana edad Søren se enfrentó a uno de los sentimientos que motivarían su producción como escritor: la melancolía. Asistió con pena a los cinco años al funeral de uno de sus hermanos. El pequeño descubrió cómo desde tan corta edad parecía como si la suerte de la providencia se diera en contra de los suyos. Así, vio partir de su lado a tres de sus hermanas y a dos hermanos más. Eran Pedro y Søren Kierkegaard los dos hermanos restantes de siete. Como si fuera poco, soportó la muerte de su madre tras una grave enfermedad y la de su padre en el año 1838 cuando Søren cargaba apenas con veintisiete años. La muerte de éste le permitió el reconocimiento de un secreto paterno, a saber: cuando aún Michael Pedersen - padre de Søren- era joven, maldijo su suerte, vociferando en contra de Dios en lo alto de una montaña a razón de los mediocres trabajos por los que tenía que pasar en Jutlandia -norte de Dinamarca- (Larrañeta,
2002, p. 11). Kierkegaard creyó aun más en la suerte de la predestinación y se entregó a la creencia de que al igual que la mayoría de sus familiares él fallecería antes de los treinta y tres años, tenía la fuerte convicción de que así lo querría la providencia. Aquel vestigio oscuro de muerte le imprimió en el espíritu la más grande de las melancolías, la misma que le llevó por los caminos de la escritura, de la fe y la fantasía.

Søren fue un hombre distinto, uno entre tantos, no sólo por la calidad y claridad de su pensamiento, sino también por la maravilla de su escritura y además por la bella manera con la que se entregó a las fricciones del amor y la seducción, él las vivió, las sintió y las sufrió: era un romántico y tuvo que aceptarlo. El contexto fue preciso; Dinamarca asistió a la recepción del pensamiento romántico de las novelas de Shakespeare, al tratamiento poético del ideal de la vida de los poetas alemanes Schiller y Goethe y a la recepción del idealismo alemán con su máximo exponente: Hegel, autor éste último al que Kierkegaard trataría de descifrar.

Bajo dicho marco intelectual Søren se educó en la Universidad de Copenhague, gracias a las ayudas de su padre quien era un brillante comerciante. Estudió filosofía, teología y literatura, todo acompañado de una drástica orientación cristiana. Søren era un gran estudioso, ya en la Universidad se habría interesado gracias a su maestro Pablo Martín Møller en temas como la libertad, la existencia en sentido limitado y paradójico (Larrañeta, 2002, p. 30) y el repudio sistemático; temas desde los cuales, con seguridad vislumbró la categoría del individuo o sujeto de la existencia. Su tesis de grado fue una 
brillante elaboración Sobre el concepto de la ironía en constante referencia a Sócrates donde según destaca Rafael Larrañeta superó la visión hegeliana de Sócrates.

De esta manera, hablar de Kierkegaard es comprometer la palabra de un pensador relacionado con la existencia, de allí, la oposición a todo sistema elaborado que no determine al sujeto como el centro de todo y que no lo postule como el sentido desde el cual toma forma la realidad. De acuerdo con dicha existencia o con ese estar en el mundo, el autor se propone determinar ciertos estadios de la existencia -estético, ético y religiosoen relación con la libertad, la angustia y la desesperación del sujeto.

Así, lo estético, se presenta como lo inmediato y lo libre de todo compromiso, aparecen el seductor y el amante quienes no habitan en lo exterior de la realidad, su interioridad es la realidad misma a la cual le agregan una configuración poética y emotiva del existir. El seductor vive del deseo, del engaño, del placer y no determina la belleza de una mujer como el motor de su existencia, sino la belleza de las mujeres, seduce y llena de plenitud a la seducida, no se compromete. Por otra parte, el amante se enamora, vive del amor del alma -el más puro-, vive en, para y por lo bello, por lo amado, pero a la vez sufre porque algo le impide -exterioridad-amar lo bello, amar como aman los amantes verdaderos, por ello es infeliz. El momento ético llega tras la conciencia de compromiso acompañado por el humor que en este caso ya no se interpreta como goce placentero de la vida sino como disfrute de mi compromiso -responsabilidad-, la ilustración más clara de la vida ética es el matrimonio. Lo religioso se da tras la conciencia de mi fe y de mi lugar en el mundo ante Dios, el absurdo y la paradoja lo justifican y muestra de ello es la actitud de Abraham quien se convierte en padre - caballero- de la fe en virtud de lo absurdo y en virtud de la paradoja. Por tanto, la fe es la justificación de la religiosidad del sujeto, porque es la que permite hacer el salto hacia lo eterno, la religión es de esta manera existencia, la que se goza renunciando a toda generalidad para estar ante Dios -particularidad-.

Cabe anotar que dichos estadios de la vida no son ni cíclicos, ni esquemáticos, ni sistemáticos y no corresponden para nada a una escala de la existencia. El sujeto que se reconoce en su libertad debe encontrarse preparado para dar un salto, ya sea, de un estadio a otro o a uno sólo. Ningún estadio es anterior a alguno, es más, los estadios de la vida según, como los presenta Kierkegaard, son determinantes en aquellos sujetos que son concientes de su existencia y que tomando dicha experiencia se atreven a "existir". Los estadios de la vida se identifican en aquellos - pocos-individuos que se reconocen entre muchos, que reconocen su angustia (realidad de la libertad, en tanto que posibilidad ante la posibilidad), su desespero (el dolor de la existencia o enfermedad mortal), la melancolía (el phatos del alma) y el sufrimiento (la naturaleza de la existencia). Søren Kierkegaard reconoció todo esto, existió y le agregó a su vasta melancolía una carga emocionante de fantasía que antepone a todo estadio la escenificación poética de la vida, ya que sólo los poetas -según Søren- son quienes reconocen las maravillas de la realidad en lo sencillo y son quienes plasman la totalidad del existir en su fantasía por medio de la evocación. Entonces, dirá Shopenhauer: "El poeta es el espejo de la humanidad y presenta a ésta la imagen clara y fiel de lo que siente".

De acuerdo con lo anterior, se deduce que Søren Kierkegaard es un escritor que permite múltiples reflexiones en relación con los temas propuestos en sus obras, temas que se encuentran elaborados, ya sean con perspectivas estéticas, éticas o religiosas y de las cuales se puede hablar en el sentido de maneras de la existencia. El objeto de la presente investigación es, entonces, el mar- 
co de las obras estéticas, en las que el autor esboza de manera poética y emotiva tanto las relaciones amorosas de un seductor como las frustraciones de un amante infeliz; diferenciación a la que se llega tras el reconocimiento de las características primordiales del estadio estético, a saber: elección, goce e instante en el seductor; melancolía, sufrimiento y desespero en el amante.

Así, los escritos de Kierkegaard y en gran medida los estéticos no son más que un pretexto para presentar la concepción estética de la vida, del amor, de la belleza, de la seducción, de la sensualidad y de la decepción o el sufrimiento de acuerdo con una manera de estar en el mundo. A este reconocimiento es posible llegar gracias a la retrospección que hace de sí mismo el escritor danés al intentar compararse, con el seductor y con el amante infeliz como bien llega a considerar Larrañeta. Todo esto se da como resultado, en gran medida, de la motivación que le generó el enamorarse de la danesa, Regina Olsen, una belleza hecha fantasía gracias al espíritu de Søren con quien entabló una relación poco duradera (un año) y a juzgar por las constantes referencias que hace el escritor de ella en sus obras, bastante tormentosa.

Por último, es preciso añadir que la idea es seguir en lo restante del texto al Søren que se colocó las máscaras del seductor y del amante infeliz para representar bajo términos existenciales y poéticos la decisión que le llevó a optar por sí mismo y por la soledad (Larrañeta, 2002, p. 30). Muy lejos y a la vez cerca de su Regina. Así, por esto y más, se logra considerar con Rafael Larrañeta que el secreto de Søren no era otro que el deseo por llegar a ser él mismo entre muchos (Larrañeta, 2002, p. 146).

\section{El estadio estético de la vida}

La estética en un hombre es aquello por lo cual ese hombre es, inmediatamente, lo que es.

Søren Kierkegaard

\section{Estética y Ética en la formación de la personalidad}

Dentro del marco de las obras estéticas de Søren Kierkegaard se ubica una magnifica obra, Enten Eller, la cual se dio tras el definitivo rompimiento de Søren con su prometida Regina y su viaje a Berlín, con motivo de un curso dictado por el idealista alemán Schelling. Es cierto que, la obra se encuentra escrita magníficamente en un corto período de la vida del escritor entre 1841 y 1842 . La melancolía y el sufrimiento generado tras el rompimiento habrían generado, por un lado, firmes convicciones creativas en el pensador $\mathrm{y}$, por otro, un aburrimiento terrible en el curso de Schelling.

¿En qué consiste la obra? es el mismo Søren quien en el prólogo de Enten Eller, que traduce al castellano $O$ lo uno o lo otro, se presenta como el editor de la misma, es decir, afirma haberse encontrado algunos papeles en un mueble viejo que se había comprado y haberlos ordenado según el azar. Enten Eller es la reunión de los sentimientos encontrados de Kierkegaard, es el soporte que le permitió desahogar sus penas y es, a la vez, el incentivo que utilizó el escritor para motivar la lectura de sus obras posteriores.

Así, es en este punto donde se hace necesario recordar que si bien el escritor danés gozaba de buena fama intelectual en Dinamarca, fue él mismo quien tomó la decisión de ocultar su nombre original con pseudónimos. El argumento era simple tal y como recuerda Larrañeta: 
Kierkegaard para complicar aún más el modo de situarse como individuo singular, como filósofo y como teólogo, ante el mayor problema de su vida, el problema de la verdad, tomó la decisión de firmar buena parte de sus obras con pseudónimos (Larrañeta, 2002, p. 50).

En otras palabras lo que llevó a Søren a firmar con otros nombres fue la posibilidad de tener múltiples maneras de existir a partir de la conciencia de la existencia misma en relación con la angustia, la desesperación y la melancolía.

De esta manera, el escritor danés firmó con el pseudónimo de Víctor Eremita ${ }^{2}$ para Enten Eller, algo así como el solitario victorioso, pseudónimo que termina por ilustrar lo que por ese momento ocurría en la vida del pensador. Un hombre solo y aburrido que se había encontrado por suerte y en aras de su intuición con los papeles de algunos intelectuales; los habría tomado y junto con ellos se habría ubicado hacia el interior del bosque para organizar los documentos sin que nadie le descubriese. Kierkegaard en el más alto estado de exaltación y felicidad por lo encontrado afirma "que se necesita mucha suerte para llevar a cabo semejantes descubrimientos" (Kierkegaard, 1969, p. 44), siendo ésta la manera como el Søren de carne y hueso se acompañó con los fantasmas del desespero y del dolor con razón de los recuerdos del rompimiento. Enten Eller le permitió al escritor danés triunfar en su soledad, descubrirse a sí mismo, fantasear con la angustia, ocultarse en máscaras y evocar el estadio estético de la vida. La conciencia propia de su existencia

2 Søren tenía múltiples maneras de existir, a saber: Johannes de Silentio, Constantin Constantinus, Johannes Climacus, Virgilius Haufniensis, Un casado, Frater Taciturnus, Hilarius Bogbinder, Anticlimacus y Nicolais Notabene. le llevó a considerar en un episodio musical: "La vida se me ha convertido en un potaje amargo. Y, sin embargo, tengo que beberla gota a gota, lentamente, llevando la cuenta" (Kierkegaard, 1969, p. 71).

De esta forma Kierkegaard presenta su obra y habla de dos series de papeles. Una primera que incluye multitud de tratados estéticos y otra pequeña, que habla acerca de reflexiones éticas. Lo primero que se ve en los papeles -dice Søren- son pequeños aforismos que se titulan como Diapsalmata o -en castellanopequeños interludios musicales, los cuales se encuentran ordenados según el azar y que dada su interpretación pueden resultar contradictorios. "Las obras estéticas son dadas tal y como están, a ellas mismas les corresponde defenderse" (Kierkegaard, 1969, p. 47). Los papeles estéticos se refieren a una concepción única de la vida, estética e inmediata y que nada tiene que ver con el juzgamiento que hacen de ella los documentos éticos según afirma Søren. Enten Eller es, entonces, un somero accidente provocado por el escritor danés que puede interesar a muchos y a pocos o en otras palabras y como su mismo editor recalca: "Tanto si lo lees como si no lo lees, te arrepentirás” (Kierkegaard, 1969, p. 56).

Ahora bien, es necesario destacar que es en algunos apartados de Enten Eller donde se logra apreciar de manera significativa lo que llamamos la concepción estética de la vida. Una concepción que consiste en el elegir, ya sea, para bien o para mal, de acuerdo con la naturaleza de la personalidad. Este elegir es lo mismo que el aut-aut con el que el escritor danés pretende hacer notar la importancia de la elección. Y bien dice: "Te repito lo que tantas veces te he dicho, o más bien te lo grito: O lo uno o lo otro" (Kierkegaard, 1970, p. 7). El elegir dentro del estadio estético de la vida se convierte así en una solemnidad. Elegir de acuerdo con la naturaleza de la personalidad hace el alma más digna porque -según afirma el pensador danés- "la grandeza no consiste 
en esto o en aquello, sino que se encuentra en el hecho de ser uno mismo" (Kierkegaard, 1969, p. 33).

La vida estética que elige el hombre es una vida inmediata, una vida en la que la existencia es bella si existe un motivo para elegir; una vida que bien es interiorizada en razón de lo crucial de la existencia y que puede caer en melancolía al ser reprimido lo elegido y en desesperación al dudar de la fuerza de la personalidad. Es ésta una vida del instante, del goce placentero, del deseo, es una vida que se apodera con todo de la libertad y que la eleva hasta su máxima expresión dada en la fantasía y en la representación. Es ésta la vida-estética-una realización que juega con la evocación de lo bello, de lo magnífico y de lo grandioso; una vida que se divierte con la duda que es la desesperación del espíritu porque al final se elige; es ésta la vida que arriesga la realidad porque la transforma; es ésta una vida que se da en la ironía; una vida que compromete todo el existir; una vida que se encuentra entre los límites de la pasión de lo erótico y el desespero producido por la angustia de no saber si se obtiene o no alguna cosa. Así, dirá Kierkegaard con relación a la vida estética:

Parece pues, que toda concepción estética de la vida es desesperación, y que todo individuo que vive estéticamente es un desesperado, lo sepa o no. Pero, si lo sabe, y tú lo sabes, se impone una forma superior de la existencia (Kierkegaard, 1969, p. 53).

Entonces, se puede agregar algo, a saber: Es ésta, la vida estética, la más elevada, una vida que puede bien ser criticada pero que no tiene punto de comparación con ninguna otra, porque para hablar de esta vida hay que decidirse a elegir y hay que atreverse a vivirla, ya que, este vivir estéticamente se relaciona según el pensador, no sólo con la sensibilidad en el sentido griego de la palabra sino también con la existencia en su plenitud.

El estadio estético, así entendido, abarca desde, el elegir como categoría inmediata que se da en el instante, hasta, las tres categorías propias del estadio, a saber: la propia inmediatez, la compresión finita y la ironía; categorías éstas que se relacionan una con la otra, ya que, son todo lo que comprende al sujeto en su existencia. De esta manera Kierkegaard dirá: "La razón por la cual el que vive estéticamente no puede explicar en un sentido superior es que siempre vive en el instante y siempre su saber es, hasta cierto punto, relativo y limitado". El sujeto mismo se hace a partir de todo lo anterior, es pura espontaneidad, libertad de elección, vida basada en el placer, en el goce o disfrute de las sensaciones, en el ahora, lo finito y lo temporal; es un sujeto individual en quien se oculta la verdad de la existencia. Muestra de ello es el seductor reflexivo que se presenta como un profundo conocedor de todas y cada una de las características de su objeto, es un irónico amante que llena de plenitud a su amada para luego desaparecer la relación e impregnarlo todo de una ausencia fantasiosa; él es un hombre que prefiere el goce al que se llega lento y es a la vez un hombre que goza de su existencia, es un profundo conocedor de sí mismo. Por otro lado, el caso del amante es distinto, él aunque se conoce en lo estético, prefiere volver sobre la melancolía y por el amor a lo eterno decide quedarse con lo infinito y lo atemporal, es un hombre que sabe de sí mismo y que se queda con lo absoluto, sin embargo, este hombre elige a pesar de no vivir una vida cien por ciento estética.

Por último, cabe anotar que si bien Søren Kierkegaard, se encontró los papeles desordenados de Enten Eller, él resulta ser mucho más que el editor de los escritos. Se da en la obra como un pensador o escritor que logra establecer diferencias radicales entre la con- 
cepción estética y ética de la vida de acuerdo con las analogías a su propio estilo de existencia, analogías que abarcan toda soledad, toda melancolía, todo amor por lo eterno y toda fantasía poética. Es entonces tanto a Víctor Eremita como a Søren Kierkegaard a quienes se les deben asignar las caracterizaciones del estadio estético de la vida, y digo esto porque si revisamos las distintas obras del escritor danés, las propias de su puño y letra o bien las que se encuentran bajo la etiqueta de un pseudónimo, constataremos en mucho que allí se dan ciertas críticas elocuentes a la vida estética de acuerdo con el compromiso en lo ético o la fe en lo religioso.

\section{La seducción estética como fantasía desde el seductor}

Entonces se regocija mi alma, late mi corazón, se enciende la pasión. Esta sola muchacha, la única en el mundo entero, ha de pertenecerme, ha de ser mía. Que Dios guarde el cielo, mientras yo la guardo a ella.

Juan

Diario del Seductor

Cuando Søren Kierkegaard editó Enten-Eller, no lo hizo por mera rutina o gracias a sus dotes de escritor, él se colocó la máscara de seductor con motivo del aún y para siempre permanente recuerdo de Regina y se permitió evocar la realidad fantasiosa presentada en el Diario del Seductor para tratar de huir aún más de su amada. El mismo Kierkegaard afirma en su Diario Íntimo hacia 1853 que "Diario del Seductor estaba escrito a propósito para rechazar a su Regina" (Kierkegaard, 1955, p. 385). Así, la narración que compone las vivencias del seductor se da como una representación mágica que realiza el escritor danés, no sólo para ahondar en la melancolía de su interior y su soledad sino también para hablar del romance con Regina bajo formas poéticas y existenciales, como anota Larrañeta (2002, pp. 35-39), esto todo en paralelo con dos personajes: Juan el seductor-que transmite la faceta seductora, poética y fantasiosa de Søren-y Cordedia - que no es nada menos que la imagen de Regina, una mujer de belleza descomunal tan lejana como el cielo y tan cercana como un recuerdo--

De esta forma, es preciso dirigir la mirada hacia el Diario del Seductor que abarca las características fundamentales de la vida pensada estéticamente y a la vez presenta al seductor como el personaje, a partir del cual se puede pensar la realidad de manera poética, ya en las primeras páginas del diario se afirma: "El susodicho titulo -seductorarmoniza completamente con el contenido en su totalidad. Su vida ha sido un intento de realizar la tarea de vivir poéticamente" (Kierkegaard, 2006, p. 312).

El Juan de Kierkegaard es un seductor que se rinde ante el erotismo, que seduce con una fineza de espíritu capaz de penetrar en las más pequeñas fibras sentimentales de su amada; que se entrega a la pasión mientras contempla el cuerpo de la misma y es quien llena de una poesía total que transforma todo dolor, sufrimiento o desazón en amor y en fantasía. Esta obra resulta ser un ejemplo claro de lo que ya se ha afirmado antes acerca del estadio estético de la vida, algo así como un momento en el que todo es inmediatez, elección, belleza, goce e instante, un momento en el que el seductor admite la existencia, la vive y es conciente de ella.

La escena de la vida es para el seductor una especie de irrealidad que no habita en la exterioridad, es una obra de teatro fantástica en la que él como seductor teme a los engaños comunes prefiriendo mejor ser quien engaña, dándose así a un acto donde lo único interesante es la vida suya que es toda conciencia y reflexión a partir de lo inmediato y de lo que puede ser elegido. 
Lo poético es ese plus que él aporta. Este plus es la poeticidad de la que él goza en la situación poética de la realidad, lo que retoma bajo la forma de reflexión poética [...] el goce es aquello para lo que su vida entera se encuentra hecha (Kierkegaard, 2006, p. 313).

Es así como se puede anotar que el seductor es un verdadero existente, la escena es su interioridad, la belleza es el objeto de su deseo, la fantasía es su realidad y la seducción es el engaño acompañado del verdadero amor. Para él el seducir es una tarea que tiene que ver con el alma porque es ella misma quien se motiva cuando ve lo bello y hay inclusive algunas otras pocas almas que reconocen esta labor, la labor poética del seductor, ya que: "para una mujer, ser la elegida de un seductor es como para el fruto ser picado por un pájaro, porque el seductor es un buen conocedor [...] un fino conocedor" (Kierkegaard, 1955, p. 386). Y se llama engaño a la seducción porque lo único que queda de ella en últimas son los recuerdos y es así como en el atrevimiento del seductor y en la perplejidad de la mujer se encuentra lo interesante del instante, no hay escapatoria, el seductor cree en sus dotes espirituales y es capaz de conducir a una mujer hasta distancias inimaginables.

Ahora bien, ha comenzado entonces el reconocimiento de la seducción del esteta a partir de la fantasía. Juan la ha visto. Es una mujer majestuosa que viste como las diosas y que parece caminar sobre nubes, es todo un misterio, desde el primer instante en que Juan la ve decide hacerla suya y decide además tramar lo que sea necesario con tal de llegar a ella. Se llama Cordelia. Es hermosa. Camina por las calles sin saber que existe un hombre poco cercano a ella que le ama mientras ella vuelve a su casa. Cordelia ha aparecido y ha dejado en el alma del seductor una huella profunda sin siquiera mirarle a los ojos, esta huella es bastante onda, tanto como para pensar que desde ahora todo lo que venga en adelante deberá ser provechoso y la maldita casualidad -como el mismo Juan le denomina-deberá traer de nuevo a Cordelia, deberá presentársela a los ojos, para así poder él contemplar su belleza eterna en un nuevo instante.

De Juan se puede hablar demasiado, mientras la busca hace feliz una angustia desesperada, sueña a Cordelia y la dibuja por todo lugar, la piensa, la ve, la observa, afirma que se encuentra dentro de sí misma como ocupada en sus pensamientos y acerca de sus ojos dice:

Sus ojos son grandes y radiantes; al mirar en ellos se descubre su oscuro brillo, el mismo que permite intuir su profundidad, pues resulta imposible acceder a ellos; son nítidos e inocentes, tiernos y tranquilos, llenos de picardía cuando sonríe (Kierkegaard, 1955, p. 337) ${ }^{3}$. Juan está enamorado y afirma que resulta interesante que su alma reconozca que lo está mientras, por otro lado, Cordelia aún ni se imagina alguno de los sentimientos que se desarrollan en Juan cuando ella aparece.

Pasa el tiempo, Juan se ha acercado mucho más, ahora ya la conoce y la saluda. Ha sido su inteligencia la que le ha permitido insertarse en la casa misma de su amada para gritarle en silencio que es ella la elegida, la única, la mujer por la cual él sería capaz de atravesarlo todo tan sólo por un instante. Ella no se impresiona aún, muy seguramente con el paso del tiempo necesario para la seducción, que puede ser mucho y a la vez poco, ella misma se sorprenderá tanto como quien ve un esplendido sol luminoso en el amanecer después de horas eternas de lluvia en una oscura y tenebrosa noche. Juan deberá gritar

3 La narración en el fragmento original se encuentra en tiempo pasado, con razón de la exposición del apartado he considerado pertinente cambiar el tiempo a presente. 
a viva voz, atacar, y penetrar en el corazón de Cordelia cuando llegue el instante preciso.

El seductor se encuentra dentro de sí y contempla a su Cordelia, aún la ve un poco lejana pero no menos maravillosa. La quiere sin amigas y la quiere para él; la pretende alejada de toda la realidad mientras juega en sueños con la imagen de su amada; quiere conocer la totalidad del espíritu de Cordelia y luego atacar; se dedica a fantasear profundamente en el amor y la observa sin más, le parece encantadora. Juan la conoce y reconoce su orgullo, no importa, aún se afana, ella debe ser suya. Él emprende la labor con una fuerte herramienta bajo el brazo: la paciencia y con razón, ya que, debe enredarla en una inmensa red de amor de la cual ella ya no pueda escapar y desde allí penetrar en el instante, hacerla suya y huir, a todo esto sólo se llega con paciencia y con la fuerte convicción de lograr lo que se quiere.

Ha comenzado el verdadero plan, Juan envía a su amigo Edvard para que sea él quien conquiste a Cordelia, lo tiene todo calculado y arriesga, Edvard es un tipo frío y aburrido que no sería capaz nunca de conquistar a una mujer tan eterna como Cordelia. El plan consiste en guiar a Edvard por el sendero de la conquista, Juan siempre estará ayudándole en todo lo que necesite mientras en el fondo lo que verdaderamente interesa es insertarse aun más en el ambiente que rodea a Cordelia, penetrar fuerte e ironizar, acercarse a ella como un amigo para luego desorientarlo todo, sacar del camino a Edvard y hacerla suya. Edvard lo hace bien a pesar de su timidez, orienta sus actos tras la guía de Juan quien cada que se encuentra más cerca de Cordelia quiere confesarlo todo. Edvard no cae en cuenta y tras poco tiempo pierde.

Ha sucedido y el plan ha sido perfecto. Juan se ha acercado a Cordelia y le ha desorientado, le ha cambiado la vida, las sensaciones y el palpitar, le ha confundido, sorprendido y conmovido; le ha dicho que es ella la mujer de sus sueños y le ha dicho también que es la elegida y esta vez con voz bien entonada. Juan ha pasado de ser un hombre que soñaba a uno que ahora tiene en el instante el deseo, a uno que ahora logra llevar de la mano a la seducida, a su Cordelia, a su única, a su mujer. La ha alcanzado, la ha atrapado a pesar de su orgullo, ha logrado seducirla estéticamente y con razón afirma: "Me embriaga pensar que ella está en mi poder. ¡Una feminidad pura e inocente, transparente como el mar y, sin embargo, profunda como éste, sin ningún presentimiento del amor!" (Kierkegaard, 1955, p. 377).

Juan la hace suya, hace crecer una inmensa y eterna llama de amor en el pecho de Cordelia, la mira a los ojos y le grita en silencio: "Cuando yo haya llevado las cosas al punto en que hayas aprendido qué es amar y qué es amarme, el noviazgo se romperá como una forma imperfecta y tú me pertenecerás"(Kierkegaard, 1955, p. 375). Juan es conciente del límite de la seducción y a pesar de ello eleva aún más el corazón y el alma de Cordelia y le dice: “¿Qué soberanamente ha dotado la Naturaleza a esta joven; sus puras formas tersas, su profunda inocencia femenina, la claridad de sus ojos! - ¡todo me embriaga!" (Kierkegaard, 1955, p. 377). Mientras todo sigue, Juan disimula perfecto y no teme a la contradicción mientras no se la descubra, ama a Cordelia en el instante y la engaña con razón de lo bello.

Se acerca el final, Juan ha hecho que Cordelia se aburra pero jamás ha dejado de darle una sola gota de amor. Se ha separado, ella ha tenido que viajar y él se ha servido de sí mismo para lograr que sea ella quien lo deje. El seductor ha aprendido mucho de Cordelia y a pesar de su experiencia quisiera no dejarla, la ama, la recuerda y dentro de sí afirma: "Lo que puedo asegurar a cualquier muchacha que confía en mí es, sobre todo, un trato perfectamente estético, por más que siempre acabe 
siendo engañada; pero ella consta también en mi estética [...]" (Kierkegaard, 1955, p. 378). Así Juan es conciente de todo y entiende lo difícil que es dejar a quien se ama, "sin embargo ejerce una gran violencia en contra de sí mismo a fin de lograrlo" (Kierkegaard, 1955, p. 378).

Ha llegado el momento definitivo, Juan se comunica con Cordelia por medio de cartas y en ellas pretende hacer extensivo su arte, quiere fortalecer con cada uno de sus movimientos el amor que en ella reside y hacerlo eterno. Él mismo considera: "Ella tiene su libertad; pero es a mí a quien debe pertenecer. Sería una estupidez que el noviazgo la ate, lo único que quiero es poseerla a ella en su libertad" (Kierkegaard, 1955, p. 382). El seductor se impacienta, sufre, no teme, resiste y se apoya en los recuerdos que hacen el logro de lo bello algo magnifico. Se dirige a ella con palabras poéticas, se queda en su fantasía y le dice:

Cordelia Mía, ¡Cordelia Mía! si quieres, te rapto ¿me lo ordenas? [...] Agárrate; si el mundo llegase a su fin; si nuestro ligero carruaje desapareciera bajo nuestros pies, nosotros seguiríamos abrazados pese a todo, suspendidos en una especie de armonía (Kierkegaard, 1955, pp. 391-392).

Juan se sale con la suya, el cambio se ha producido; Cordelia se encuentra confundida y ama como nunca. Ella aún combate y se resiste mientras él vuelve al lado de su fantasía y al lado del erotismo de los recuerdos, mientras él evoca a su Cordelia y a la vez pretende que sea ella quien se aleje. Magnífica contradicción, pero Juan es más que eso, Juan es un hombre que hace todo con el más puro amor. ¿Se entiende? Llega el instante verdadero, se aman, son fugaces en el tiempo y se separan. Juan la evade en compromiso y muy dentro de sí afirma:
Amar a una es demasiado poco; amarlas a todas es superficial; conocerse a uno mismo y amar al mayor número posible, hacer que la propia alma esconda todos los poderes del amor de manera que cada una obtenga su alimento determinado mientras que, sin embargo, la conciencia lo capta todo - eso es el placer, eso es vivir- (Kierkegaard, 1955, p. 362).

Ahora bien, cuando llega el final de todo, cuando el instante termina y cuando la magia de la seducción no soporta ya la concreción de la conquista se da paso al sufrimiento. Tanto Cordelia como Juan pierden radicalmente la paz y la tranquilidad de su espíritu. Cordelia se siente inmersa en un nudo imposible de desatar al cual ha llegado tras el descubrimiento del alejamiento de su ahora amado y le dice:

Huye a donde quieras, aun así soy tuya; márchate al fin del mundo, aun así soy tuya; ama a otras cien jóvenes, aún así soy tuya; sí, en la mismísima hora de la muerte he de ser tuya. Has osado engañar a una persona de modo que has llegado a serlo todo para mí; pues ahora quiero dedicar toda mi alegría a ser tu esclava, tuya soy, tuya, tuya, tu maldición (Kierkegaard, 1955, p. 319).

Y luego, un día más tarde, el seductor añade: "¿Por qué una noche como ésta no habría de durar hasta lo infinito? Ahora todo se acabó" (Kierkegaard, 1955, pp. 433-434).

Por último, cabe destacar que dentro de tanta maravilla, tanta poesía, tanta expresión y tanta belleza hay algo que es seguro: la seducción de Juan el seductor es un arte fantasioso que se encarna en el engaño por medio del amor, un arte al que se llega tras estar ligado a la conciencia de sí mismo. Es éste el arte 
en el cual se esconde profunda e íntimamente Søren Kierkegaard, un arte que le sirve de máscara para disimular en algo su renuncia a la más bella de todas, su Regina, un arte que le aproxima al amante infeliz con razón de su amor por lo eterno, ya que, si bien Søren parte de la seducción no cumple a cabalidad con el plan del seductor, él no busca nuevas mujeres o nuevas sensaciones, Søren poeta seduce y conquista para luego renunciar y anclarse de la mano de la eternidad en el recuerdo de su amada, siempre quiere volver y es allí donde se impone la resistencia, como en el caso de Juan, quien a pesar de todo termina dudando acerca de si es posible deshacerse poéticamente de una joven.

\section{El amor como melancolía desde el amante infeliz}

\author{
¿Qué ama el amor? \\ Infinitud. \\ - ¿Qué teme el amor? \\ - Límite.”
}

\section{Juan. Diario del Seductor}

Durante los últimos años de su vida Kierkegaard se dedicó a la labor de escritor religioso y fue en ese momento en el que descubrió cómo "la Iglesia Danesa habría convertido al Cristianismo en un adulterio por medio de sus estructuras oficiales" (Larrañeta, 2002, p. 115). Søren fue ante todo un creyente que postulaba la verdadera fe en relación con la existencia, según el pensador danés, se llega a una relación con Dios cuando se es capaz de apropiarse de la particularidad y de relacionarla con lo absoluto, muestra de ello son sus escritos religiosos como: Temor y Temblor, Las obras del amor o la Ejercitación del cristianismo ${ }^{4}$. Pero más allá de dicha

4 Rafael Larrañeta es preciso en definir que la labor y de dichas obras aún habría algo que atormentaba el espíritu del escritor danés.

Por ejemplo en Temor y Temblor, texto firmado con el pseudónimo Johannes de Silentio, el escritor danés se dedica a distinguir las posibilidades que tiene el existente religioso ante la prueba de fe y sin embargo, aún, allí mismo, en un apartado se refiere a una mujer que le habría podido cambiar las rutas de la existencia, sin duda, se trata de su amada, de Regina quien leía todas sus obras y es a ella a quien le dice entre líneas:

Yo he reconocido a una persona que pudo haber redimido mi vida en cierta ocasión, si hubiese sido magnánima [...] "Soy del todo consciente de lo que podría emprender, pero no me atrevo a ello porque temo que luego me viniese a faltar la fortaleza y me arrepintiese" (Kierkegaard, 1998, p. 82).

El debate espiritual de Kierkegaard no sólo era acompañado por la grandeza de la fe, además de ello, se encontraba perplejo ante la pasión transmitida por la seducción y la angustia provocada por el amor infeliz, como ya se ha recalcado. Dadas las aproximaciones críticas a la Iglesia de su país y la intuición del final de sus días, Søren decide realizar un balance de su relación con Regina tras ocho años de rompimiento, es decir, el pensador danés jamás logró reponerse del golpe que habría generado la ruptura, jamás logró olvidar a Regina y jamás logró dejar de amarla aún cuando ella ya se había casado con otro hombre. Así, en su Diario Íntimo fechado con el 24 de agosto de 1849 Søren titula las páginas con un atrayente título: "Mi relación

obra literaria de Kierkegaard se encuentra divida en tres grandes bloques temáticos: uno de carácter estético, otro de índole filosófica y un tercero netamente religioso, donde se encuentran las obras arriba referenciadas. 
con "Ella" - En forma un poco poética" (Kierkegaard, 1955, p. 379).

Allí, Kierkegaard sitúa su relación con Regina en el plano de lo espiritual y logra por medio de las acotaciones poéticas vislumbrar el porqué de su enamoramiento y el posterior rompimiento con su amada. Acerca del enamoramiento dice:

Durante aquel tiempo permití que su vida se vinculara con la mía [...] subí con ella hasta su casa. Henos aquí a solas en el saloncito. Ella está un poco nerviosa. Le rogué que ejecutara algo para mí, como lo hacía habitualmente. Lo hizo, pero no logré mi intento. Entonces, de pronto, tomé la partitura, la cerré con impetuosidad arrojándola sobre el piano, y le dije: -¿Qué importa la música? ¡A "usted” es a quien quiero desde hace dos años!- Enmudeció (Kierkegaard, 1955, p. 380).

Regina habría quedado anonadada ante la fuerza del Søren enamorado y le habría aceptado en seguida, él logró al igual avisarle de su profunda melancolía y hacerse a la prioridad en todo, Regina ahora se encontraba perdidamente enamorada, pertenecía a Søren.

Así y al poco tiempo Kierkegaard anota acerca del rompimiento: "Pero al día siguiente, en mi fuero interno descubrí que me había equivocado. Un penitente como yo, con mi vida y mi melancolía...debía bastar" (Kierkegaard, 1955, p. 381). El enamorado se arrepentía, reflexionaba y se alejaba, nada más, Regina sufriría bastante a su lado, la melancolía resultaba demasiado profunda y fuerte. Y ella, tan sólo ella, tan perfecta, tan paciente, cedía ante todo, no había salida el pensador consideraba que lo mejor era romper.

Desde allí surgieron los sentimientos encontrados que provocaron tantas fantasías y tantas tristezas, por un lado era Regina quien se rendía, quien rogaba por Søren, quien le imploraba que no le dejara y por otro era él mismo quien se lamentaba en su interior. ¿Qué hacer? Él lloraba largas horas en la noche e incluso afirmaba que si no hubiese sido por su melancolía habría sido feliz al lado de Regina. Además de todo, el pensador se sentía presa de una protesta divina, no podía ser, no podía seguir, atrás quedaban los eternos momentos, los más bellos, las horas en que su amada se rendía en honor al verdadero amor ante él. Era cuestión de manejarlo todo, sólo un poco de dureza y algo de engaño, mentir, ocultarse y sufrir, él mismo dice: "Fue un tiempo de tremendas penas; verse obligado a ser tan cruel, y amar, no obstante, como amaba yo. Ella luchaba como una leona; de no haber creído yo que era una protesta divina, habría vencido" (Kierkegaard, 1955, p. 383).

¿Qué decir? La ruptura definitiva llegó y Regina quedó toda en su desesperación. $\mathrm{Su}$ padre incluso visitaba a Søren con el propósito de que no la abandonara. Él optó por la soledad, por sí mismo, dentro de su ser hasta ahora se avecinaban los más crueles tormentos, los recuerdos le llenaban la cabeza de ausencia y de melancolía. No había ruta a seguir, tan sólo la suya, la que pudiera elaborar, renunciar y resignarse, escapar, armarse de un irónico valor y luchar contra el dolor, hacerse tan fuerte como para entender que el verdadero amor es personal y que es desde allí donde se hace eterno. Huir al daño que se le podría causar a una hermosa mujer que lo era todo, que lo aguantaba todo, que lo entendía todo, sí, huir, correr hacia el refugio interno, sufrir, ser cobarde, engañarse y no ceder.

Pasó el tiempo, Regina se alejó de a poco y se casó, atrás quedaban ahora las luchas por un amor que clamaba felicidad, por un amor que de cerca se penetraba en lo bello y en lo perfecto. Todo lo permitió Søren, así era mejor, ella debía entender que él lo hizo por ella y ni siquiera por él. Decía: 
Así pensaba yo (¡y eso sí que es amor!); o seré tuyo, o te permitiré que me hieras tan profundamente, en lo más íntimo de mi melancolía y en mi vínculo con Dios, de manera que, aunque separado de ti, sea siempre tuyo (Kierkegaard, 1955, p. 392).

Es de esta forma como Kierkegaard mismo acepta compararse con un amante infeliz al afirmar: "Evidentemente, un amante está ciego; por consiguiente, su juicio no es objetivo; ve tal vez belleza y rasgos por completo inexistentes" (Kierkegaard, 1955, p. 386). A esta determinación llega el pensador tras esbozar de manera detallada lo que habría sido su relación con Regina, una especie de amor penitente desbordado por el interés y la pasión que provoca la seducción, para Søren "el amor es visto como una determinación de la pura interioridad" (Larrañeta, 2002, p. 65) $\mathrm{y}$ es por tanto una renuncia a lo amado con miras a lo eterno. Kierkegaard afirma ser un amante desgraciado y a la vez logra conllevar con su decisión, tanto en su alma como en la de su amada, un profundo recuerdo, una eternidad sin límites, una infinitud mágica y un sentimiento perpetuo. En últimas dirá Søren: "Al fin y al cabo, tú no puedes saber si no sería un bien también para ti que yo permaneciera a tu lado" (Kierkegaard, 1955, p. 395).

Por último, es preciso añadir que Søren considera que "al amor infeliz le corresponde que el amor esté dado y que una potencia le impida expresarse felizmente en el encuentro de los amantes" (Larrañeta, 2002, p. 42). Así, parece no quedar duda que en este caso esa potencia que impide al amor en su realización es la melancolía que le da paso al sufrimiento, a la separación y al dolor y en esto se apoya Kierkegaard para afirmar:

Aparte de mis numerosas amistades aún tengo un confidente íntimo: mi melancolía. Constantemente me hace señas en medio de mis alegrías o de mis trabajos, y entonces me llama a un lado y la obedezco, aunque corporalmente continúe en mi sitio. Mi melancolía es la más fiel amante que he conocido. ¿Qué tiene, pues, de extraño que la corresponda con todo mi amor? (Kierkegaard, 1969, p. 62).

De esta manera y llegado a este punto se hace necesario destacar que la idea de Kierkegaard al compararse con el seductor estético y el amante infeliz es precisamente lograr una retrospección de sí mismo uniendo en una o dos maneras de la existencia. El seductor, Juan, se convierte desde Søren en un profundo conocedor de lo que quiere y desea, llenándolo todo de fantasía, de poesía, de belleza, de sensualidad y de amor, mientras la seducida-Cordelia-contempla la más pura felicidad y el más puro sentimiento para luego rendirse ante su hombre, ante su Juan, quien le ha hecho eternamente suya, le ha maravillado y le ha dejado. Así, el amante infeliz, el propio Søren, se encuentra perplejo ante la maravilla de la mujer que le ha robado el corazón pero aún no el alma, entonces, regresa sobre sí mismo y sobre su melancolía, le deja, le huye y decide guardarla dentro de su alma para toda la eternidad. Ambos, el seductor y el amante son perfectas creaciones, mágicas trampas de la estética y perfectas escenas de la existencia, para quienes su director tendría algunas bellas frases, a saber: "Que lo finito y lo moral desaparezcan y quede solamente lo eterno: la fuerza del amor, el deseo infinito y la beatitud (Larrañeta, 2002, p. 45).

Finalmente, puede decirse que la lucha por la existencia es en Kierkegaard lo esencial de acuerdo con la posibilidad y la libertad del sujeto. En Søren la existencia o el existir toman forma a partir de la conciencia y de la reflexión y es gracias a ello que el sujeto 
mismo puede elegir. Así, el estilo retórico de las obras del pensador permite llegar a la creación de una imagen tanto de los personajes elaborados como de los temas tratados en relación con la existencia, ya que, o bien se existe estética-ética o religiosamente.

En últimas, aquel Søren que amaba los más finos cigarrillos y los más excelentes vinos, que optó por sí mismo en la ruta de la soledad y que desentrañó los temores de su alma para plasmarlos en la melancolía, no fue algo menos que un existente, es decir, logró lo que pocos, ser uno entre muchos y desde allí no importó más nada, ni siquiera las recriminaciones de su amada, ¿acaso estás loco? (Kierkegaard, 1955, p. 389). Ya había tranquilidad, la vida de Søren es toda fantasía, es toda eternidad y para tratar de entenderlo bastaría tan sólo con citar las palabras que él mismo quiso en su tumba, a saber: "Todavía un poco y habré vencido. Toda lucha será superada. Así podré reposar en una sala de rosas y deleitarme en eterno coloquio con mi Jesús" (Larrañeta, 2002, p. 144). Por ello este trabajo se encuentra dedicado a aquel individuo, a Søren Aabye Kierkegaard, todo por un intento de entender, si fuera posible, los suspiros y tormentos por los que suele pasar el alma enamorada.

\section{Referencias}

Kierkegaard, S. (1955). Diario íntimo. Buenos Aires: Santiago Rueda.

Kierkegaard, S. (1969). Estudios estéticos I: Diapsalmata y El erotismo musical. Madrid: Guadarrama.

Kierkegaard, S. (1970). Estética y Ética en la formación de la personalidad. Buenos Aires: Nova.

Kierkegaard, S. (1998). Temor y temblor. Madrid: Tecnos.

Kierkegaard, S. (2006). Diario del seductor. En $O$ lo uno o lo otro: Un fragmento de vida I. Madrid: Trotta.

Larrañeta, R. (2000). La lupa de Kierkegaard. Salamanca: San Esteban. 